\title{
CIÊNCIA, POESIA, FILOSOFIA: DIÁLOGOS CRÍTICOS DA TEORIA À SALA DE AULA
}

\author{
GUILHERME DA SILVA LIMA ${ }^{1}$ \\ ORCID: https://orcid.org/0000-0002-0049-5790 \\ JOÃO EDUARDO FERNANDES RAMOS ${ }^{2}$ \\ ORCID: https://orcid.org/0000-0002-1492-0997 \\ LUÍS PAULO DE CARVALHO PIASSI ${ }^{3}$ \\ ORCID: https://orcid.org/0000-0002-4423-180X
}

\begin{abstract}
RESUMO: Este artigo apresenta contribuições teóricas e empíricas para discutir o uso de poesias na educação científica. As contribuições teóricas perpassam pelas discussões entre: a ciência, a arte e o ensino; a imaginação e a criação nas atividades literárias e científicas; e as interfaces entre a estética e a cognição. As contribuições empíricas analisam poesias produzidas por estudantes do $9^{\circ}$ ano do ensino fundamental em aulas de Ciências. As análises baseiam-se nas contribuições teórico-metodológicas propostas por Vigotski, que permitiram a produção de três categorias para analisar as poesias produzidas, a saber: questionamento da realidade, questionamento do saber humano e posicionamento responsivo. Os poemas exibiram diferentes orientações para a realidade, com emprego de conceitos trabalhados em sala de aula para sustentar os posicionamentos dos estudantes. Tal fato nos mostra a apropriação de ferramentas culturais (conceitos), visto que há o uso das mesmas em um contexto autônomo. As análises indicam que as poesias contemplaram aspectos cognitivos, emocionais e responsivos frente aos assuntos abordados, ao passo que sugerem que o uso de poesias em práticas didáticas de ciências pode contribuir com o desenvolvimento da formação crítica dos estudantes.
\end{abstract}

Palavras-chave: Ensino de Ciências; Poesia; Histórico-cultural; Ciência e Arte.

\section{SCIENCE, POETRY, PHILOSOPHY: CRITICAL DIALOGS FROM THEORY TO CLASSROOM}

\begin{abstract}
This article presents theoretical and empirical contributions to discuss the use of poetry in science education. The theoretical contributions broach the discussions between: science, art and teaching; imagination and creation in literary and scientific activities; and the interfaces between aesthetics and cognition. The empirical contributions analyze poetry produced by students of the last year of middle school in science classes. The poems used concepts taught in the classroom to support the students' position who presented different orientations to reality. This fact indicates the appropriation of cultural tools (concepts), since they are used in an autonomous context. The analyzes are based on the theoretical-methodological contributions proposed by Vygotsky, which allowed the production of three categories to analyze the poetry produced, namely: questioning

\footnotetext{
${ }^{1}$ Instituto de Ciências Exatas e Biológicas, Universidade Federal de Ouro Preto, MG, Brasil. <glima@ufop.edu.br>

${ }^{2}$ Campus Agreste, Universidade Federal de Pernambuco, PE, Brasil.. <joao.framos@ufpe.br>

${ }^{3}$ Escola de Artes, Ciências e Humanidades, Universidade de São Paulo, SP, Brasil. <lppiassi@usp.br>
} 
of reality, questioning of human knowledge and responsive positioning. The analyzes indicate that the poems have contemplated cognitive, emotional and responsive aspects in relation to the subjects addressed, while they suggest that the use of poetry in science education can contribute to the development of the critical formation of the students.

Keywords: Science teaching; Poetry; Cultural-historical; Science and Art.

\section{CIENCIA, POESÍA, FILOSOFÍA: DIÁLOGOS CRÍTICOS DE LA TEORÍA HASTA EN EL AULA}

RESÚMEN: Este artículo presenta contribuciones teóricas y empíricas para discutir el uso de la poesía en la educación científica. Las contribuciones teóricas corren a través de las discusiones entre: ciencia, arte y enseñanza; imaginación y creación en actividades literarias y científicas; y las interfaces entre estética y cognición. Las contribuciones empíricas analizan la poesía producida por estudiantes en el noveno grado de la escuela primaria en las clases de ciencias. Los análisis se basan en las contribuciones teórico-metodológicas propuestas por Vigotski, que permitieron la producción de tres categorías para analizar la poesía producida, a saber: cuestionar la realidad, cuestionar el conocimiento humano y el posicionamiento receptivo. Los poemas exhibieron diferentes orientaciones para la realidad, utilizando conceptos trabajados en el aula para apoyar las posiciones de los estudiantes. Este hecho indica la apropiación de herramientas culturales (conceptos), ya que se utilizan en un contexto autónomo. Los análisis indican que la poesía incluía aspectos cognitivos, emocionales y receptivos en relación con los temas abordados, al tiempo que sugiere que el uso de la poesía en las prácticas de enseñanza de las ciencias puede contribuir al desarrollo de la educación crítica de los estudiantes.

Palabras clave: Enseñanza de las ciencias; Poesía; Cultural-histórico; Ciencia y arte.

\section{INTRODUÇÃO}

Assim como outras/os pesquisadoras/es (CARTWRIGHT, 2007; GIRALDELLI; ALMEIDA, 2008; GROTO; MARTINS, 2015; SILVEIRA; ZANETIC, 2016), temos investigado o uso da literatura na educação científica. Muitas/os professoras/es usam poemas e letras de música em suas aulas de ciência, intuindo possivelmente não apenas o despertar de um interesse especial da/o estudante, mas algo que vai além: a maneira única como a literatura é capaz de nos falar do mundo, que é - para falar o mínimo - complementar à visão científica das coisas. Desejamos trazer neste trabalho contribuições teóricas e empíricas que nos permitam avançar além da tendência mais propositiva que tem caracterizado muitos dos trabalhos a respeito do tema. Antes de nos debruçarmos sobre o poema e sobre alguns resultados que observamos ao levá-lo para as situações educativas, pretendemos rever algumas propostas de articulações didáticas entre ciência e arte - particularmente a literatura e os poemas - e estabelecer uma linha teórica que fundamente tal proposta.

Zanetic, já há algum tempo, tem trazido a proposta de articular artes e ciências no ensino. Em sua tese, apontava essa possibilidade e mencionava obras nas quais enxergava "laços fortes entre literatura e física" (ZANETIC, 1990, p. 105). Zanetic (2006b) expõe as aproximações em autoras/es clássicas/os da literatura, como Stendhal, Zola, Dostoiévski, entre outras/os. Em outro trabalho, Zanetic (2006a) aponta possibilidades didáticas tanto de poemas como de canções de música popular brasileira. Em um artigo anterior (ZANETIC, 2005), seguindo uma linha muito próxima, aponta também alguns poemas com aproximação à ciência, desde Dante até Keats. Zanetic (2005, p. 24) afirma que "as operações culturais desses dois campos do conhecimento - literatura e ciência - acabam se cruzando e, talvez, apresentando uma certa complementaridade de construção sobre a realidade". É justamente em torno dessa complementaridade que centramos nossa argumentação. 
Reis e colaboradores (2006) também abordam a aproximação entre a ciência e a arte na educação, apresentando um breve panorama histórico das relações entre a pintura e as artes visuais com a física, e aproximam-se da ideia de complementaridade:

As concepções artísticas e científicas são coerentes, levando a interpretações semelhantes a respeito do funcionamento do universo. Artistas e cientistas (ou filósofos naturais) percebem o mundo da mesma forma, apenas representam-no com linguagens diferentes (REIS et al., 2006, p. 72).

Talvez não seja um consenso essa ideia de tanta similitude entre as concepções artística e científica, mas, de todo modo, o vínculo que as/os autoras/es demonstram entre esses dois âmbitos é bastante consistente. Gouveia (2004), por sua vez, entende que há certa valorização da cultura artística em detrimento da científica como elemento de formação cidadã e democrática. Em seu artigo no qual defende a aproximação da física à literatura, apresenta diversos poemas com conteúdo físico, de renomados poetas portugueses, e afirma que "ainda persiste por vezes a ideia de que só uma cultura artístico-literária (dita humanista) é capaz de transmitir um sistema de valores democráticos" (GOUVEIA, 2004, p. 40). Para essa autora, "impõe-se um conceito de cultura que abranja as visões artístico-literária e científica, estabelecendo pontes entre elas" (GOUVEIA, 2004, p. 41). Silva (2006, p. 5) também enxerga um conflito arte-ciência, mas o situa em torno de uma dicotomia entre um âmbito lúdico-imaginativo da primeira e outro lógico-racional atribuído usualmente à segunda:

A escola, muitas vezes, nega as semelhanças que existem entre arte e ciência, ao basear-se em uma visão maniqueísta, na qual a arte estaria no campo da imaginação, da invenção, do lúdico, do ilógico, do falso ou não verdadeiro; e a ciência - seu polo oposto, como discurso - corresponderia ao domínio do racional, do lógico, do comprovado, do verdadeiro (SILVA, 2006, p. 3).

Argumenta a autora que, ao contrário dessa visão, a ciência exige constantemente do cientista o recurso à imaginação: "o cientista é levado a imaginar, a pressupor, por mais rigorosos que sejam seus esquemas, eles, os esquemas, atuam no desconhecido, e, às vezes, o texto científico pode incorporar essa inexatidão" (SILVA, 2006, p. 5). Ferreira (2010) aponta que esse tipo de dicotomia não existia até a Renascença, mas que a partir do período moderno surgiu "um tipo de pensamento que separou esses saberes e os manteve isolados em suas especialidades, como se não houvesse possibilidade de diálogo entre eles" (FERREIRA, 2010, p. 263). Segundo ele, as duas vertentes, ou as duas culturas, como aponta Snow (1959), "passaram a assumir características, linguagens, métodos, processos cognitivos e vinculações epistemológicas independentes e diferenciadas e, às vezes, também opostas" (FERREIRA, 2010, p. 263). Para esse autor, a partir desse momento, enquanto a ciência adquire cada vez mais uma perspectiva lógico-matemática, as artes incorporam a subjetividade e evitam a padronização metodológica e a redução do mundo a princípios generalizantes (FERREIRA, 2010, p. 264). A partir disso, toca em um ponto que consideramos fundamental: "a obra de arte, (...) continua produzindo significados independentemente do que foi imaginado pelo seu criador. Ela produz sensações e modos abstratos de pensamento que escapam aos domínios da racionalidade ou da lógica" (FERREIRA, 2010, p. 264). No entanto, é justamente nessas diferenças de abordagens que se justificam a ideia de complementaridade e a aproximação arte-ciência em um contexto didático:

A utilização de diferentes linguagens artísticas que possam sensibilizar professores e alunos para um ensino de ciências mais criativo, ampliando a percepção do papel da ciência e da arte; desenvolvendo estratégias, processos, metodologias e produtos que aumentem a criatividade na formação (...); e ainda praticando um ensino que estimule a imaginação, a criatividade, a sensibilidade e a intuição. (FERREIRA, 2010, p. 263).

Isso se torna relevante na medida em que, "tanto na Arte como na Ciência, a intuição é imprescindível, pois ela articula tanto as informações oriundas da sensibilidade, da imaginação, da experiência, do desejo ou das diferentes percepções da realidade, como também produz um 
conhecimento intelectual que se baseia nos princípios da razão" (FERREIRA, 2010, p. 277). O papel da intuição e da imaginação na ciência também é mencionado por Moreira (2002), que apresenta diversos poemas que incorporam influências do conhecimento científico. Para esse autor:

Ciência e poesia pertencem à mesma busca imaginativa humana, embora ligadas a domínios diferentes de conhecimento e valor. A visão poética cresce da intuição criativa, da experiência humana singular e do conhecimento do poeta. A Ciência gira em torno do fazer concreto, da construção de imagens comuns, da experiência compartilhada e da edificação do conhecimento coletivo sobre o mundo circundante (MOREIRA, 2002, p. 17).

Um aspecto importante é que a ciência, sendo um importante componente da vida cultural, necessariamente acaba incorporada em representações artísticas, o que se torna possivelmente um dos primeiros pontos de partida quando se imagina concretizar propostas didáticas que integrem esses dois âmbitos da cultura. Em relação à canção, Moreira e Massarani (2006) observam que "a ciência e as visões sobre ela e seus impactos permeiam a cultura popular e encontram expressão através da pena de poetas e compositores", sendo que, "às vezes, temas de ciência ou conceitos dela emanados assumem papel proeminente", enquanto em outras é "apenas secundária ou incidental dentro da temática do poema musicado" (MOREIRA; MASSARANI, 2006, p. 306). Essa observação, já trazida por Zanetic (2005, 2006a, 2006b) em relação à literatura, é pontuada há bastante tempo pelo escritor e divulgador científico Bhatha (1972), que comenta e dá exemplos sobre a influência, desde os primórdios modernos, da ciência ocidental sobre as artes, com destaque para a poesia:

A revolução científica causou uma tremenda comoção na mente dos homens, conforme a ciência começou a questionar os fundamentos primários de tudo aquilo que eles haviam construído em termos de crenças sobre a ordem natural do universo (...) e em nenhum lugar esse impacto pode ser captado mais vividamente do que na literatura da época. A mudança na concepção humana de mundo se reflete nas imagens mutantes usadas nos poemas que floresceram durante a revolução científica (BHATHA, 1972, p. 129, tradução nossa).

Nessa linha, Lopes (2005, p. 416) defende que "a arte pode ajudar a popularizar a ciência porque pode contribuir para conferir emoção aos temas da ciência"; e prossegue afirmando que "a ciência é emocionante, mas o registro que se faz dela (...) não inclui o papel da intuição na prática científica - o que acentua a errônea visão dicotômica de que a ciência se baseia na razão e a arte na emoção" (LOPES, 2005, p. 416). Mas o que configura essa emoção? Segundo a autora, "é preciso beber na arte e na ciência para aprender a estranhar o habitual, para enxergar no óbvio o inusitado. As grandes descobertas surgiram do espanto diante do óbvio" (LOPES, 2005 p. 417). Compreensão similar também foi trazida pelo filósofo e divulgador da ciência Bronowski:

Um poema não oferece um certo número de alternativas, convidando-nos a escolher uma ou outra. O poema pede-nos para compará-las, mas não para julgá-las: diferentemente do teorema de Pitágoras, não é um plano de ação. Pelo contrário, o poema - a obra de arte em geral - está composto de tal forma que positivamente desencoraja o leitor a decidir qual das ações imaginárias (qual dos seus possíveis significados) é melhor e deve ser preferida (BRONOWSKI, 1998, p. 33).

A maior parte das/os autoras/es que acabamos de citar foram influenciados pelo pensamento de Bronowski, que tem como uma de suas principais preocupações as relações entre artes e ciência. A criatividade e a imaginação, aponta Bronowski (1979), têm um papel central na ciência, assim como o têm na atividade artística. O exame dessa questão configura-se como um dos caminhos privilegiados para a discussão dos pontos de contato entre a arte e a ciência como produtos culturais. Em "Science and Human Values", escrito em 1958, Bronowski aponta "que existe uma única atividade criadora, que se revela do mesmo modo nas artes e nas ciências", e prossegue afirmando que "é errado considerar a ciência como um registro mecânico dos fatos e é errado considerar as artes como fantasias 
antigas e individuais" (BRONOWSKI, 1979, p. 33). Para o autor, em ambas as atividades nunca se trata de uma mera tarefa de colecionar e catalogar fatos. A ciência, assim como a arte, não é produzida mecanicamente, e exige da parte de quem a pratica um esforço criador. Porém, parece haver uma tendência a considerar a ciência como um trabalho criativo estéril. Bronowski destaca que muitos consideram a atividade científica como mera catalogação de fatos e observações:

As pessoas que leram Balzac e Zola não se iludem com as afirmações destes escritores de que mais não fazem do que registrar os fatos. (...). Todavia, os mesmos leitores trazem solenemente consigo desde os bancos da escola esta tonta imagem do cientista fixando por qualquer meio mecânico os fatos da natureza. (BRONOWSKI, 1979, p. 77).

Ao discorrer sobre importantes contribuições científicas, o autor sustenta que, para chegar à sua concepção, Copérnico não poderia se valer da observação das trajetórias do planeta ao redor do Sol para propor o sistema heliocêntrico, assim como seria inviável a Kepler sair testando todas as possibilidades de relações matemáticas entre grandezas até chegar à lei dos cubos e quadrados. Tanto um quanto outro tiveram que criar - ou imaginar, como sugere Edgar Allan Poe (1848) no poema em prosa Eureka - para chegar ao resultado a que chegaram, assim como faz um poeta.

Isso não implica, porém, uma identidade entre o ato criativo da ciência e da arte: "o artista na sua criação [abre] uma dimensão de liberdade que está vedada ao cientista. Tenho insistido em que o cientista não registra simplesmente os fatos, mas deve conformar-se com os fatos" (BRONOWSKI, 1979, p. 34). A ciência, portanto, não se confunde com a atividade artística em relação à criatividade, vistos os limites impostos pelos dados empíricos e pela coerência teórica.

O processo criativo, que é fundamental na constituição do conhecimento científico, assim como nos outros âmbitos da cultura humana, deve sua manifestação a outra capacidade humana fundamental: a imaginação. Bronowski coloca em pauta a questão, apontando como a imaginação é um fator subjetivo fundamental tanto no fazer científico quanto no trabalho artístico. Em seu ensaio "The Reach of Imagination", Bronowski (1977, p. 28) aponta "a imaginação como a faculdade de produzir imagens e de usá-las mentalmente, arranjando-as de diferentes modos. Esta é a faculdade especificamente humana, a raiz comum da qual se originam a ciência e a literatura, que se desenvolvem e florescem juntas".

Bronwski aborda o sentido afetivo quando situa a imaginação no contexto da liberdade que a mente humana é capaz de propiciar. A imaginação passa a ser o fundamento central da brincadeira, do prazer, da possibilidade de explorar novas ideias e sensações, processo que vem da infância e que encontra manifestações maduras tanto na atividade artística como na científica:

A capacidade de traçar imagens que representem o que está ausente e de usá-las para experimentar situações imaginárias dá ao homem uma liberdade que nenhum animal tem. (...) Ao brincar, a criança é movida por esse prazer, e o mesmo acontece com o artista e também com o cientista. (BRONOWSKI, 1998, p. 27).

Para Bronowski, a linguagem atua na imaginação pela possibilidade de expressar ideias e imagens e manipulá-las mentalmente, dando caráter único à forma como cada indivíduo apreende e expressa a realidade e as ideias: "não há dois seres humanos que usem exatamente a mesma linguagem, mesmo se forem gêmeos idênticos" (BRONOWSKI, 1998, p. 27). É nesse ponto que Bronowski identifica a capacidade ilimitada de inovação, um dos aspectos-chave da criação artística: "ao ler um poema, todos vemos as mesmas palavras, mas cada um de nós torna o poema até certo ponto diferente, e pessoal, ao escolher diferentes pontos, tonalidades distintas, ao criar novas analogias na mente de cada um" (BRONOWSKI, 1998, p. 27). Assim, mais do que possibilitar a variedade infinita de manifestações artísticas, a linguagem permite também a variedade infinita de interpretações distintas de cada manifestação, de acordo com a singularidade das experiências do sujeito. Mas se a imaginação permite a liberdade, em que ponto essa liberdade terá que ser confrontada com a realidade? Se a 
imaginação pode tudo, não corremos o risco, ao enfatizá-la, de estarmos fugindo da realidade? O autor fala desses limites e destaca a diferença entre eles na ciência e na arte:

Não se pode chegar a uma conclusão sem uma experiência real, porque nada que imaginamos pode ser transformado em conhecimento efetivo até que façamos sua conversão em realidade. O teste da imaginação é a experiência, na literatura e nas artes, como na ciência. Na ciência, o experimento imaginário é testado confrontandoo com a experiência física; na literatura, a concepção imaginada é testada confrontando-a com a experiência humana. Na ciência, a especulação superficial é desprezada porque falsifica a natureza; e a obra de arte superficial é desprezada porque não está de acordo com nossa própria natureza (BRONOWSKI, 1977, p. 27).

Bronowski, portanto, vê a ciência e a arte como formas distintas de apreensão da realidade. Comparando a forma como a ciência e a poesia estabelecem uma relação com a realidade, o autor afirma que a ciência "organiza nossa experiência em leis, sobre as quais baseamos nossas ações futuras", ao passo que a poesia "é outro modo de conhecimento, em que comungamos com o poeta, penetrando diretamente na sua experiência e na totalidade da experiência humana" (BRONOWSKI, 1998, p. 20). Entendemos que essa riqueza cognoscitiva implícita no ato criativo artístico e científico proporciona uma apreciação estética refinada e profunda, bem como a percepção das potencialidades e dos limites impostos pela realidade humana e natural e sua superação, com o impulso que a cultura viva suscita.

Todos os vários aspectos da imaginação trazidos por Bronowski, que permitem voos para muito além de uma descrição neutra da natureza, em direção a saltos epistemológicos no âmbito existencial, são o que o ato educativo não deveria negar ao estudante que está diante da ciência que, queiramos ou não, é o que é trazido a ele institucionalmente, dentro das nossas salas de aula.

\section{AS INTERFACES DIDÁTICAS ENTRE ESTÉTICA E COGNIÇÃO}

Todos os vários aspectos da imaginação trazidos por Bronowski, que permitem voos para muito além de uma descrição neutra da natureza, em direção a saltos epistemológicos no âmbito existencial, são o que o ato educativo não deveria negar ao estudante que está diante da ciência que, queiramos ou não, é o que é trazido a ele institucionalmente, dentro das nossas salas de aula.

As práticas educativas orientadas contam com diversas ações para a promoção de uma educação estética. Não estamos nos pautando exclusivamente nas proposições realizadas na disciplina escolar "Artes", mas nas várias atividades desenvolvidas nas escolas, centros culturais e museus que permitem o desenvolvimento da percepção estética de jovens e crianças.

Camargo e Bulcagov (2008) trazem contribuições para se pensar a educação estética. Ao abordarem a temática, as autoras defendem a importância da educação estética para a superação das relações automatizadas que as pessoas estabelecem com o mundo. Tais relações estão baseadas em uma realidade instrumental, que é contraproducente à formação crítica. Esse modelo instrumental é reproduzido, sobretudo, nas escolas, que deveriam atuar para desenvolver a consciência das/os jovens para que elas/es se percebam como singulares e capazes de gozar de suas autonomias e respeitar a autonomia alheia. Nesse sentido, a presença da estética deve ser compreendida como aliada da educação, ao passo que esta não pode se constituir somente por meio de componentes disciplinares isolados. A vivência estética pode promover o desenvolvimento da percepção, da sensibilidade, além da interpretação mais plural da realidade (CAMARGO; BULGACOV, 2008). Para as autoras,

A sensibilidade estética surge nesse processo de percepção dos objetos que transcende a dimensão utilitária direta e ultrapassa uma atitude unívoca diante da realidade. $\mathrm{Na}$ relação estética o sujeito entra em contato com o objeto mediante a totalidade de sua riqueza humana, não apenas sensível, mas também intelectiva e afetiva (CAMARGO; BULGACOV, 2008, p. 470).

Para além do sensível, intelectual e afetivo, não podemos negligenciar o papel da estética no desenvolvimento psíquico e suas relações com a imaginação. Segundo Vigotski (2004b), a imaginação é 
fruto de operações que articulam experiências vivenciadas pelo indivíduo. De acordo com a perspectiva histórico-cultural, podemos entender a imaginação humana como um complexo produzido pelas experiências, que são articuladas de diferentes formas pelo cérebro. As criaturas míticas exemplificam de forma simples a produção de complexos, como o Centauro: ser quadrúpede, meio homem, meio cavalo. Nesse caso, a produção imaginária (centauro) é criada pela decomposição e justaposição de seres existentes. Contudo, a criação pode adquirir formas mais variadas e/ou elaboradas. Nas palavras de Vigotski (2004b, p. 14): "a atividade criativa da imaginação depende diretamente do quão rico e variado é a experiência prévia do sujeito, pois essa experiência proporciona material com o qual os produtos da fantasia são produzidos".

A dependência entre imaginação e realidade não impõe exclusivamente a reprodução de elementos existentes. Na maioria das vezes, há uma criação estética evidentemente nova, mesmo que tenha sido produzida pela justaposição de unidades reais. A produção imaginária pode ainda ser cristalizada em algum meio material: nesse caso, ela passa a constituir o mundo real e afetar outras pessoas, isto é, pode ser incorporada como vivência humana que permite, inclusive, a mobilização de novas produções imaginárias. Algumas obras de arte podem ser consideradas como cristalização da produção imaginária humana. Elas são criações que possuem origem na imaginação e podem ser capazes de influenciar a consciência social e produzir relações entre o fato imaginário e o mundo real.

A produção imaginária, assim como qualquer outra produção humana, carece de acabamento estético, seja ela uma figura mítica, uma história fantástica ou mesmo uma máquina capaz de revolucionar a atividade humana. Tal acabamento é produzido pelo sujeito e condicionado pelas relações sociais, históricas e econômicas que produzem o contexto da produção estética (MEDVIÉDEV, 2012). Nesse sentido, a imaginação e a estética são capazes de ampliar o corpo de referência dos indivíduos, além de promover um tipo de relação entre elementos qualitativamente diferentes.

O uso de obras de arte ou de atividades que estão baseadas em produções artísticas é frequente na educação. Existem inúmeras histórias e contos que foram produzidos para representar determinados conceitos ou comportamentos sociais, sem contar tantas outras expressões artísticas (teatro, artes plásticas, fotografia, cinema etc.) que são tão ricas quanto a literatura. As interpretações dessas obras permitem diversas apreciações, mas é comum a abordagem de questões morais para as crianças e adolescentes.

Vigotski (2004a) critica as correntes que valorizam os aspectos morais relacionados à obra de arte em detrimento de outros aspectos resultantes da experiência estética. Além disso, ele evidencia a atividade responsiva presente na contemplação estética e destaca que o psiquismo se baseia em uma dinâmica entre os fatores cognitivos e emocionais. Ao criticar a preeminência da educação moral por meio da experiência estética, Vigotski não menospreza a capacidade de compreensão das crianças de uma obra complexa, uma vez que as crianças podem muito mais do que "limitar-se a uma poesia de asneiras e futilidades como se fosse a única acessível à compreensão infantil” (VIGOTSKI, 2004a, p. 324-325), como é comum na literatura juvenil. Acrescenta ainda que:

A nossa escola, ignorando inteiramente o fato psicológico da diversidade de possíveis interpretações e conclusões morais, sempre procurou enquadrar qualquer vivência estética em um conhecido dogma moral e se contentou com assimilar esse dogma, sem suspeitar de que o texto artístico frequentemente não só não ajuda a assimilá-lo como, ao contrário, infunde uma concepção moral de ordem justamente oposta (VIGOTSKI, 2004a, p. 27).

Vigotski (2004a) não nega os efeitos morais desencadeados por uma experiência estética. Todavia, reduzir essa vivência aos acentos morais destitui da obra artística seus outros elementos característicos e sua autonomia. A defesa da valorização dos aspectos morais em detrimento dos outros sugere que a obra de arte seria um meio através do qual o autor defende uma tese moral. O principal problema dessa interpretação é a negligência com os fatores sensíveis, afetivos, cognitivos e criativos que a experiência estética pode despertar. Destacamos em especial as atividades criativas que podem ser promovidas pela experiência estética. Vigotski (2004b) enfatiza que o ato criativo se refere a um 
momento que se materializa como resultado de um longo processo produtivo. Desse modo, o ato criativo é desenvolvido por meio de diversos processos internos como a memória, a percepção, a cognição, a imaginação etc., que permitem a criação humana.

Aquilo que a criança vê e escuta fornece os primeiros pontos de apoio para sua futura criação. Ela acumula materiais com os quais ela construirá, subsequentemente, suas fantasias. Em seguida, ocorre um processo muito complexo de reformulação desse material. O componente mais importante deste processo são as dissociações e associações das impressões adquiridas através da percepção (VIGOTSKI, 2004a, p. 25).

Tais processos complexos de dissociação e associação apontados por Vigotski permitem que as crianças, por meio da dissociação, fragmentem a totalidade de certo fenômeno ou experiência em unidades isoladas, que podem ser associadas de formas diversas para a criação do novo. Além da percepção, não podemos deixar de ressaltar a importância da imaginação, caso contrário o ato criativo estaria fadado a reproduzir aquilo que já existe no mundo humano.

Outra característica fundamental da experiência estética está relacionada com a contemplação da obra, que não é uma atividade passiva. Vigotski (2004a) reconhece a necessidade da percepção sensorial para a vivência estética, mas destaca que, se ela estivesse baseada exclusivamente nisso, muitas pessoas apresentariam as mesmas percepções, uma vez que os registros fisiológicos podem ser idênticos: "a emoção estética se baseia em um modelo absolutamente preciso de reação comum, que pressupõe necessariamente a existência de três momentos: uma estimulação, uma elaboração e uma resposta" (VIGOTSKI, 2004a, p. 333).

A contemplação de uma obra artística contém, portanto, um elemento responsivo, que é chamado pelo autor de síntese criadora secundária: atividade responsável pela síntese da totalidade artística presente na obra; tais processos proporcionam desdobramentos da experiência estética. A síntese criadora secundária pode se constituir como um elemento que impulsiona a imaginação humana, como resposta aos anseios e dilemas da humanidade. Assim, a imaginação não se relaciona com a estética apenas durante a produção criativa, mas também na apreciação da produção estética.

Pino (2006) contribui com essa discussão ao destacar que na vivência estética o ser humano realiza transformações das funções biológicas em funções simbólicas determinadas pela ação da cultura. Tais transformações envolvem o desenvolvimento tanto de habilidades biológicas relacionadas à percepção sensível quanto da apropriação das ferramentas culturais propostas pela sociedade. Há uma relação dialética entre esses fatores, que irão determinar a formação estética. A apropriação de ferramentas culturais passa necessariamente por um processo de significação e produção de novos sentidos determinados pela atividade cognitiva. Assim, a experiência estética proporciona tanto o uso de ferramentas culturais quanto o desenvolvimento de novos sentidos.

Considerar a experiência estética como ato responsivo implica reconhecer que esta atividade permite a ampliação das ferramentas culturais dominadas pelo sujeito e com elas contribui. A responsividade carrega consigo o processo de produção de sentidos que primeiramente é instaurado na relação entre o sujeito e a obra e depois pode ser expandido para as relações entre o sujeito e as situações vivenciadas por ele. Sem dúvidas, reconhecemos que emoção e cognição são funções distintas do psiquismo humano, ainda que desempenhem papéis equivalentes no seu desenvolvimento. No entanto, emoção e cognição são funções que podem se relacionar e possuem a mesma origem, a saber: a relação social. Para Vigotski, o desenvolvimento psíquico ocorre sobre uma base dinâmica e integrada, constituída por elementos cognitivos e emocionais (GONZÁLEZ REY, 2000). Entendemos que a responsividade é uma característica da experiência estética que evidencia as relações que podem emergir entre a emoção e a cognição.

Dentre os pós-efeitos da vivência estética, Vigotski aponta o efeito moral e o efeito cognitivo; ressaltamos também o efeito criativo, que pode ser mobilizado a partir da experiência estética. Ressaltamos que os pós-efeitos permitem "ampliar a nossa concepção de algum campo de fenômenos, levar-nos a ver esse campo com novos olhos, a generalizar e unificar fatos amiúde inteiramente dispersos" (VIGOTSKI, 2004, p. 342). 
Tendo em vista as ideias acima expostas, entendemos que propor atividades que articulem elementos cognitivos e emocionais proporcionados pela vivência estética pode produzir novas situações capazes de corroborar com os processos de ensino e aprendizagem. Nesse sentido, destacamos a relevância das obras produzidas por estudantes com finalidades educativas. Entendemos que estas são atividades didáticas e que os propósitos de sua produção por vezes diferem dos propósitos da obra de arte. Contudo, concebemos que atividades desenvolvidas por estudantes, como a produção de poesias, histórias e desenhos, possuem características capazes de evidenciar diversas dimensões de sua interação com o saber, seja em seus aspectos afetivos ou cognitivos. Diferentemente de atividades tradicionais de avaliação ou de produção de texto que estão, em sua maioria, centradas nos aspectos conceituais dos objetos de aprendizagem, a produção de poesias, histórias e desenhos permite que as crianças e os jovens expressem outros elementos decorrentes da aprendizagem, como a relação afetiva que se estabeleceu com o objeto e os posicionamentos responsivos frente aos assuntos abordados.

\section{UMA SEQUÊNCIA DIDÁTICA DE CIÊNCIAS COM PRODUÇÃO DE POESIAS}

Como forma de aplicar e situar objetivamente as formulações teóricas aqui desenvolvidas, apresentamos a análise de poesias produzidas por estudantes em uma escola no interior de São Paulo. As poesias foram produzidas por estudantes do $9^{\circ}$ ano do ensino fundamental durante duas aulas de Ciências.

As aulas foram desenvolvidas em uma escola do município de Piracicaba-SP durante o primeiro semestre do ano de 2013. Destacamos que a investigação respeitou todas as diretrizes e princípios éticos na pesquisa com seres humanos, conforme as orientações da resolução do Conselho Nacional de Saúde - CNS 196/96. A escola apresentou, no mesmo ano, um IDEB de 5,2 e atingiu a meta projetada para o período. Além disso, Piracicaba é uma cidade em que $94,45 \%$ das crianças e adolescentes em idade escolar estão matriculados em instituições formais de ensino. Se nos focarmos apenas no ensino fundamental, $97,5 \%$ das crianças do município estão matriculadas nas redes de ensino. Os indicadores da cidade apontam, ainda, que apenas 1,41\% das crianças entre 11 e 14 anos são analfabetas. Apesar dos atuais indicadores, somente 63,98\% da população maior de 18 anos possui ensino fundamental completo, condição que influencia na expectativa de anos de estudo na cidade: 10,22 anos. A condição de vida da população é maior que a média brasileira e próxima à média estadual, tal como podemos ver na comparação dos Índices de Desenvolvimento Humano nos Municípios (Tabela 1).

Tabela 1. Dados de IDHM de Piracicaba em comparação com espacialidades conexas.

\begin{tabular}{|c|c|c|c|c|}
\hline Abrangência espacial & IDHM & IDHM Renda & $\begin{array}{c}\text { IDHM } \\
\text { Longevidade }\end{array}$ & $\begin{array}{c}\text { IDHM } \\
\text { Educação }\end{array}$ \\
\hline Brasil & 0,727 & 0,739 & 0,816 & 0,637 \\
\hline Estado de São Paulo & 0,783 & 0,789 & 0,845 & 0,719 \\
\hline São Paulo (Capital) & 0,805 & 0,843 & 0,855 & 0,725 \\
\hline Piracicaba (SP) & 0,785 & 0,797 & 0,848 & 0,717 \\
\hline
\end{tabular}

Fonte: Atlas de desenvolvimento humano no Brasil (Dados de 2010). Disponível em http://www.atlasbrasil.org.br

As poesias produzidas pelas/os estudantes constituíram a penúltima atividade de uma sequência didática (SD) proposta pelo professor de ciências sobre o tema micro e macrocosmos. Participaram da atividade 38 estudantes, sendo 26 do sexo feminino e 12 do sexo masculino com idades variando entre 13 e 16 anos. Selecionamos quatro poemas para análise no presente trabalho, considerando-se os seguintes critérios:

- Mobilização temática, isto é, a presença de temas trabalhados pelo professor durante a sequência didática.

- Complexidade das produções: poesias que articulam as temáticas com elementos da expressão literária (prosopopeia, paradoxo, eufemismo etc.), evidenciando esforços estéticos e criativos. 
- Representatividade, ou seja, a capacidade de as poesias apresentadas sintetizarem as categorias encontradas nas análises.

Apresentamos para a análise a transcrição das poesias. Os nomes atribuídos às/aos estudantes autoras/es dos poemas são fictícios e selecionados a partir de uma tabela sequencial padronizada de nomes. São três poemas escritos por estudantes do sexo feminino e um de estudante do sexo masculino, constituindo aproximação com a distribuição da amostra.

A SD conteve nove aulas e foi produzida tendo como base o Modelo Topológico de Ensino (GIORDAN, 2015). As atividades tiveram como eixo articulador uma problematização tecida sobre aspectos científicos, éticos e filosóficos. É relevante destacar os principais objetos de ensino da $\mathrm{SD}$, visto que eles podem estar presentes nas poesias produzidas: mito da caverna; notação científica; partículas elementares; bóson de Higgs; microcosmo; e macrocosmo. A SD propôs atividades que contemplaram tanto a interdisciplinaridade quanto o horizonte social. A interdisciplinaridade é evidente, dada as correlações entre saberes científicos e filosóficos, ao passo que, por meio do horizonte social, a SD contemplou alguns temas extremamente recentes na mídia naquele período, como o bóson de Higgs.

A problematização teve como pergunta desencadeadora a questão: você sabe com quem está falando? (LIMA, 2016). A partir dessa pergunta, o professor de ciências problematiza as dimensões da realidade micro e macroscópica, buscando questionar a dimensão do ser humano no Universo. Os métodos utilizados pelo professor durante as aulas foram diversificados, contando com leitura de textos, uso de vídeos, além de exposições, discussões e trabalhos individuais e em grupo. Na maioria das propostas realizadas, as/os estudantes tiveram papéis ativos, lendo, discutindo e produzindo outros materiais além das poesias (LIMA, 2016). Para a produção destas, o professor explicou aos estudantes a natureza da atividade e apresentou para eles algumas poesias, dentre elas "Mar português", de Fernando Pessoa (2002), e duas outras feitas por alunos no ano anterior. O professor sugeriu que as atividades desenvolvidas na SD fossem lembradas durante a produção das poesias.

Para a análise, baseamo-nos nas contribuições de Vigotski (2009), por isso tomaremos como unidade de análise os significados das palavras. Utilizamos a análise de conteúdo para demarcar os sentidos expressos nas poesias, apresentando três categorias:

I. Questionamento da realidade - dimensão ontológica dos objetos discursivos abordados na poesia, de modo que são apresentadas reflexões acerca das características da realidade;

II. Problematização do saber humano - crítica ao conhecimento humano, ao passo que são apresentadas as limitações e as potencialidades do mesmo;

III. Posicionamento valorativo - as apreciações e valores que as/os estudantes apresentam referentes aos assuntos abordados na poesia.

Ressaltamos que as três categorias propostas se referem a um produto de um processo interno de dissociação e associação, típicos do ato criativo. É válido notar que as categorias também se aproximam das visões apresentadas por Bronowski, e demais autores, para o processo de criação artístico e científico. Nelas encontramos o aspecto afetivo, na terceira categoria; o aspecto da linguagem e da imaginação, na primeira categoria; e a visão das/os autoras/es sobre a ciência, na segunda.

Por serem atividades escolares, é fácil observar e entender que dentre os elementos dissociados e associados estão os conteúdos desenvolvidos durante a aplicação da SD. Todas as categorias articulam aspectos cognitivos, afetivos e responsivos. Além disso, quando pertinente, apoiamo-nos em elementos da análise semiodiscursiva de linha greimasiana (FIORIN, 2011) como parâmetro de estudo para corroborar e aprofundar as análises.

Ressaltamos, porém, que os aspectos cognitivos são mais evidentes nas categorias questionamento da realidade e questionamento do saber bumano, ao passo que é possível notar o domínio e a apropriação de novas ferramentas culturais (conceitos). Os aspectos afetivos, por sua vez, estão mais evidentes na categoria posicionamento valorativo, pois, a partir das posições dos estudantes, é possível correlacionar seus valores frente aos assuntos mobilizados nas poesias. Os aspectos criativos podem ser vistos na totalidade da poesia produzida. A investigação contou ainda com a triangulação entre pares para a validação das análises e conclusões. 


\section{III.1. Eis a questão}

Podemos notar aspectos relacionados ao questionamento do saber bumano e ao posicionamento valorativo na poesia "Eis a questão" (ANA, 14 anos).

\section{Eis a questão}

1. Ficamos presos a coisas que achamos ser real

2. Mas real não pode ser.

3. Por que o real é grandioso

4. E tudo não podemos conhecer.

5. Achamos que somos o centro

6. mas o centro não podemos ser

7. Existem imensidões que

8. ainda vamos conhecer

9. De onde viemos?

10. Para onde vamos?

11. O que conhecemos?

12. O que iremos conhecer?

13. Estamos a sós, nessa grande extensão?

14. Isso eu não sei,

15. Mas deixo em aberto esta questão,

16. porque ainda iremos conhecer.

Na primeira estrofe, a estudante adota, predominantemente, os significados já estabilizados das palavras usadas, de modo que a poesia problematiza o que está no discurso e não extrapola a interpretação literal. Entendemos que a exceção ocorre com a expressão "coisas que achamos ser real" (1), que faz referência ao saber humano. A partir dessa interpretação, a estudante questiona aspectos do conhecimento humano sobre a realidade, estabelecendo uma relação entre o mundo natural e o saber humano, que pode ser incongruente, além de ser incompleto.

Do ponto de vista semiodiscursivo, o primeiro passo é verificar se o texto se situa na categoria narrativa, estabelecida pela transformação de um sujeito frente a um objeto (FIORIN, 2011, p. 27). Observamos que o sujeito da narrativa (FIORIN, 2011, p. 29) é "nós", representando um universal do gênero humano, na medida em que não especifica a figura de uma pessoa ou grupo, muito embora se possa argumentar que o "nós" possa se referir aos estudantes, ou à própria turma. O caráter geral dos enunciados, porém, sugere a alternativa mais generalizante. A transformação pressuposta é a obtenção (jamais lograda) das respostas explicitadas nos versos da terceira estrofe, constituindo assim uma narrativa de privação (FIORIN, 2011, p. 29). Com isso, estabelece-se uma tarefa, representada por um objeto (FIORIN, 2011, p. 31) almejado, que seria a busca constante desse conhecimento, e que se destina a ser um dia obtido, conforme explicitado na última estrofe.

A dificuldade de tudo conhecer é representada pela imensidão $(3 ; 7 ; 13)$, que opera como o antissujeito (TATIT, 2005, p. 193), configurando uma barreira à obtenção do objeto de valor. A segunda estrofe mostra um reconhecimento dessa limitação, e também uma aceitação desta condição, entretanto vislumbrando no final a consecução de tal missão ainda não cumprida. Em termos de espacialidades, próprias do nível discursivo, observamos a constituição de um espaço universal caracterizado pela dimensão (grandioso, imensidão, grande extensão) que se apresenta como figura da própria meta a ser atingida (o conhecimento). A temporalidade expressa-se de modo indefinido, mas orientada ao futuro $(8 ; 12 ; 16)$, e é figurada em possíveis outros (estamos sós?), cujo encontro pressuposto representa mais um elemento da consecução da missão do sujeito "gênero humano".

Concomitantemente, a estudante problematiza o saber humano a partir do conflito entre a totalidade e a particularidade. Baseada nessa disputa, a estudante evidencia a possível disparidade entre 
o conhecimento e a realidade, de modo que podemos sintetizar o pensamento apresentado na poesia com a seguinte pergunta: é possível conhecer a realidade sem conhecer a totalidade? Tal questão não se apresenta como um paradoxo entre a totalidade e a particularidade, mas, sobretudo, como crítica ao conhecimento humano, que é incapaz de saber o real se não conhecer a totalidade.

A segunda estrofe apresenta a mesma estrutura composicional e racional da primeira, contudo altera o objeto discursivo, que passa a ser os seres humanos. Além do deslocamento do objeto discursivo, há uma orientação que privilegia os sentidos estabelecidos pela produção narrativa, em detrimento dos sentidos estabilizados pelos significados das palavras. Esse efeito é favorecido pela palavra centro, que possui diversos sentidos e, no contexto de uso, refere-se à centralidade do ser humano no Universo. Assim, a abordagem critica o sentimento humano acerca de sua posição no Universo e destaca a apreciação responsiva e os valores da estudante sobre o assunto, que entendemos como seu posicionamento valorativo, uma axiologia que atribui à tal descentração um valor eufórico (FIORIN, 2011, p. 23). Esse posicionamento, inclusive, denota uma possível orientação moral da estudante frente à realidade, visto que pode nortear sua atuação no mundo.

Em síntese, enquanto na primeira estrofe há predominância de uma interpretação que critica a equivalência entre o conhecimento e a realidade, na segunda estrofe a produção estética se pauta nas apreciações e valores da estudante sobre a posição do ser humano no Universo, reconhecendo suas limitações, mas, ao mesmo tempo, indicando que, no futuro, essa relação pode mudar.

\section{III.2. Ó Universo}

Em seu turno, o questionamento da realidade é evidente na poesia produzida por outra estudante (BRUNA, 15 anos):

\section{Ó Universo}

1. Ó universo

2. Você que é infinito

3. Como é grande, majestoso

4. e bonito.

5. Nos deixa acreditar

6. que somos o seu centro,

7. que mandamos em tudo

8. aqui dentro.

9. Nós sabemos que não passamos de nada.

10. Nada somos.

11. Nada seremos,

12. e para o nada vamos.

13. Mesmo sabendo disso,

14. como no mito de Platão.

15. Só vemos o que nos é mostrado,

16. pensando que é a imensidão.

17. O universo,

18. com toda a sua grandeza

19. deve nos ensinar

20. e com generosidade

21. cedermos nosso lugar

22. Pois até o Sol,

23. com o seu brilho dourado 

24. Cede seu lugar a Lua
25. para que ilumine a noite
26. com seu brilho prateado

O início da poesia destaca-se devido à evidência de elementos afetivos e eufóricos. A primeira estrofe inteira expressa o sentimento de contemplação e admiração do Universo, que é descrito por adjetivos que qualificam características apreciadas pela estudante. Mas, ao mesmo tempo que o Universo é admirado, ele atua como um fator negativo (antissujeito), por permitir que o sujeito realize o seu desejo de acreditar que é o centro, como apontado na segunda estrofe, oposto ao objeto de valor, que novamente aqui é a descentração humana.

Nesse poema, novamente é mobilizada a figura de um "nós", indefinido e genérico, que, no entanto, não constitui um sujeito narrativo, função que é desempenhada pelo ator "Universo", constituído pessoa mediante o diálogo em segunda pessoa (você). A instauração do espaço como pessoa estabelece um sujeito cujo objeto é um ensinamento (cedermos nosso lugar). A associação do Universo com uma figura divina pode ser considerada a partir dessa actorialização, que inclusive sugere passagens comumente associadas ao campo religioso, como nos versos 10 a 12 (nada somos, nada seremos e para o nada vamos). Contraditoriamente à sugestão de descentramento humano mobilizada na segunda estrofe, a autora subordina a própria missão dessa divindade/Universo aos desígnios humanos, como nos versos 5 ("nos deixa acreditar") e 19 ("deve nos ensinar").

Nessa poesia, a estudante utiliza inclusive um dos conteúdos trabalhados em sala de aula para questionar a realidade. Platão é citado para corroborar com a negação da realidade apresentada pela estudante; essa referência é apresentada após o posicionamento cético frente ao ser humano feita na estrofe anterior, visto que "não passamos de nada", "nada somos", "nada seremos" e "para o nada vamos". A negação da realidade está diretamente relacionada ao mito da caverna escrito por Platão, em que se apresenta uma alegoria para fazer referência à ilusão vivenciada pelo ser humano. A composição dessa poesia representa o desenvolvimento cognitivo da estudante sobre este referente, visto que foi capaz de utilizá-lo de forma coerente em um contexto de autonomia, isto é, indica apropriação desses conteúdos trabalhados em sala.

Essa poesia não apresenta somente a categoria questionamento da realidade: as categorias problematização do saber humano e posicionamento valorativo também estão presentes. A primeira em menor grau, mas evidente na segunda estrofe, que apresenta a ideia de controle do Universo e/ou da natureza ("que mandamos em tudo aqui dentro") como uma crença. Entendemos que o controle do Universo e/ou da natureza se refere ao conhecimento humano. O posicionamento valorativo da estudante demarca a insignificância humana perante o Universo, a negação da posição central do ser humano no Universo, bem como o valor do Universo que, comparativamente à humanidade, possui valor superior.

O poema tem um narrador que fala em terceira pessoa do plural, com um discurso que englobaria muitas pessoas ou a humanidade como um todo. Além disso, usufrui da animação de seres inanimados em sua produção estética, no caso: o Universo, o Sol e a Lua. A animação é evidente pelos verbos e expressões que indicam ações como: "nos deixa acreditar"; ó universo (...) deve nos ensinar"; "o sol (...) cede seu lugar para que a lua ilumine". Tais alusões podem ser interpretadas como uma visão teleológica da realidade, na medida em que opera com sentidos de dever e de posse (o seu lugar) e finalidade (para que), o que sugere um questionamento de realidade direcionada a finalidades maiores, corroborando a associação ao campo religioso.

Diferentemente do primeiro poema apresentado, no poema "Ó Universo" são mais evidentes alguns processos de dissociação e associação feitos pelos estudantes na produção criativa. As dissociações feitas dos referentes Universo, saber humano e mito da caverna se cristalizam em unidades que carregam conotações expressas especialmente nas cinco primeiras estrofes, constituindo a sequência narrativa: contemplação do Universo e a opressão do Universo, que no poema nos permite o erro (ausência de ação), evidenciando o processo de manipulação (FIORIN, 2011, p. 29) entre Universo e humanos; ignorância do nosso saber e negação do ser; a conformação que é consolidada pelo resgate do mito da caverna, representando a fase denominada competência (FIORIN, 2011, p. 29), na qual verificamos uma tomada de consciência da condição mediante a mobilização do mito da caverna; e, por fim, a superação, que representa o processo de performance ou ação (FIORIN, 2011, p. 29), que é possível 
por meio de um processo educativo em que o Universo é o educador. Além das conotações, há a animação em que a autora atribui ações às entidades inanimadas (Universo, Sol, Lua), que no final do poema comparecem no sentido de uma sanção (FIORIN, 2011, p. 29) positiva pela adoção por parte dos humanos de sua missão de harmonização com o Universo.

Os sentidos atribuídos durante os processos de dissociação e associação corroboram com a estabilização do posicionamento valorativo da estudante. Assim, esse posicionamento é predominantemente negativo, visto que se baseia na opressão e ignorância que são conformadas, embora haja a contemplação e a possibilidade de superação.

\section{III.3. Apenas o infinito}

Apresentamos a seguir a poesia de um estudante (ARTUR, 15 anos), em que o desenvolvimento cognitivo é apresentado especialmente pelo questionamento do saber humano:

Apenas o infinito

1. Bonito e infinito

2. existe algo além do macro e micro?

3. Já que não sabermos de onde vem

4. será que vamos mais além?

5. Deus é infinito

6. assim como macro e micro

7. portanto células,

8. partículas serão algo infinito?

9. Perguntas geram respostas

10. Respostas são a solução?

11. Respostas apenas esclarecem

12. Metade dessa imensidão.

Esse poema aparenta se afastar de um modelo narrativo, constituído quase totalmente por enunciados de estado. Para Fiorin (2011, p. 27), "ocorre uma narrativa mínima quando se tem um estado inicial, uma transformação e um estado final". O verso 4, no entanto, pressupõe justamente isso: "será que vamos mais além?". Novamente o sujeito instaurado é um "nós" genérico, e sua missão é "ir mais além", representando um objeto de valor. Dessa vez, porém, as "respostas", na estrofe final, ainda que obtidas, não são suficientes para a consecução do plano, pois "apenas esclarecem metade dessa imensidão". Talvez a outra metade esteja nesse pressuposto "algo" que existe para além do macro e do micro do verso 2 .

Assim, toda a criação estética aqui presente faz referência ao saber humano, porém, em especial a última estrofe apresenta duas orientações para a abordagem. Na primeira orientação, há o reconhecimento da natureza do conhecimento, que é produzido a partir de questionamentos. Já na segunda, há uma crítica frente ao alcance do conhecimento científico, que, de acordo com o posicionamento valorativo apresentado pelo estudante, é incapaz de contemplar a imensidão do Universo, de forma aparentemente definitiva. O posicionamento valorativo apresentado na poesia fundamenta-se especialmente em aspectos cognitivos, que demarcam a compreensão desse estudante sobre o conhecimento e a realidade, bem como os valores decorrentes dessa compreensão, e mobiliza certo pessimismo disfórico quanto à possibilidade de apreensão completa do saber.

As associações criadas pelo estudante articulam aspectos divinos, reais e do saber humano. No poema, o divino é apresentado como unidade ontológica comparável à realidade, uma vez que há a comparação; todavia, o divino é o elemento base e inquestionável que sustenta a comparação com o real, que por sua vez pode ser questionado, assim como o saber humano. A presença do elemento divino no poema explicita a associação religiosa que permaneceu tácita no poema anterior, e fortalece o questionamento do saber bumano, uma vez que esse saber, ainda que implícito, se refere ao conhecimento científico, que desde sua origem nega a explicação divina ou sobrenatural para os fenômenos naturais e sociais. Fica a dúvida, porém, se o estudante realiza essa negação, subordinando Deus a uma ordem 
natural, em uma perspectiva agnóstica, ou se o promove hierarquicamente sobre a realidade. $\mathrm{O}$ uso do comparativo "assim como" no verso 6, referindo-se a Deus, sugere um paralelismo não-hierárquico, mas ao mesmo tempo sem incorporá-lo ao mesmo espaço ontológico, o que - talvez - seja a tal metade inatingível do saber humano, para além do micro e do macro.

\section{III.4. Imaginação e realidade}

Por fim, o último exemplo analítico apresenta as três categorias que encontramos, bem como os aspectos cognitivos, afetivos e responsivos relacionados com a aprendizagem (CAMILA, 14 anos).

Imaginação e realidade

1. Fora daqui existe uma imensidão

2. Ao limite do que sabemos

3. O que ainda não podemos ver

4. O que ainda faz parte da nossa imaginação

5. Existe uma realidade

6. Diferente do que sei

7. Diferente do que sabem

8. Se parassem para pensar

9. No fundo é realidade.

10. Sabemos pouco de onde estamos.

11. Podemos descobrir para onde vamos?

12. Se vamos?

13. A realidade é além do que vemos

14. Será que somos vistos?

15. Apenas um planeta

16. Onde o ser humano habita

17. Apenas uma realidade.

18. Quem sabe sua imaginação

19. Passa a coincidir com a verdade?

Esse poema situa um espaço específico que é a Terra, e utiliza em uma breve passagem a primeira pessoa, articulando uma narrativa pressuposta, mobilizada desde o "fora daqui" no primeiro verso e concretizada no verso 12 perguntando "Se vamos?". Também diferente dos demais, aqui temos o aparecimento da imaginação e de hipóteses acerca da vida extraterrestre, como indicado na indagação “será que somos vistos?". No fim, na última estrofe, há até um desejo pela aproximação entre a imaginação e a verdade. Nesse sentido, vemos que o narrador, embora reconheça a importância da verdade e sua relação com a realidade, dá um valor eufórico à imaginação, colocando-a como possível resposta a indagações sobre a realidade.

Podemos notar diversos momentos em que a poesia acima faz referência à natureza de um dos principais objetos discursivos, a realidade. Diferentemente da poesia que faz referência ao mito da caverna e possui uma orientação filosófica idealista, essa poesia claramente apresenta uma orientação filosófica realista. Em todas as estrofes, a estudante faz referência à ideia de que 'a realidade existe independentemente do conhecimento ou da percepção humana'. Tais aspectos indicam a presença do questionamento da realidade como orientação central da poesia produzida, bem como do desenvolvimento cognitivo proporcionado pela SD, haja vista a competência da estudante na articulação dos conteúdos presentes na poesia, dentre eles: realidade, dimensão do Universo e conhecimento humano - todos eles trabalhados nas aulas de ciências. O questionamento da realidade, inclusive, é correlacionado com as outras orientações presentes na poesia, a saber: problematização do saber bumano e posicionamento valorativo. A partir do estabelecimento da existência da realidade, a poesia 
argumenta que este postulado independe do fato de os seres humanos estarem cientes e acrescenta que o saber humano é limitado.

Quanto ao posicionamento valorativo, a segunda estrofe, em especial, apresenta a concepção da estudante e a tentativa de convencer o interlocutor acerca de sua defesa do realismo. A palavra realidade aparece duas vezes: na primeira, seu sentido coincide com a acepção normativa; na segunda, porém, seu significado está mais próximo ao sentido de verdade - expressão que evidencia a responsividade da estudante na produção estética. A segunda estrofe demarca ainda características que podem ser categorizadas como questionamento do saber humano, visto que, apesar de declarar limitações ao conhecimento humano, a estudante evidencia sua importância para a compreensão da realidade. Ao produzir a frase "se parassem para pensar", faz referência clara à capacidade do pensamento humano, e indiretamente do conhecimento, de reconhecer a verdade. Os aspectos afetivos dessa poesia podem ser mais facilmente observados nas duas últimas estrofes, em que são expressos os sentimentos de angústia e dúvida frente à posição do ser humano no Universo e o sentimento de esperança e desejo de que a imaginação humana seja correspondente à realidade.

As dissociações e associações presentes no poema "Imaginação e realidade" são bem distintas daquelas presentes no segundo poema, especialmente porque, neste, as combinações não possuem orientações com fronteiras tão bem definidas. É evidente, aqui, que o realismo está introjetado em toda produção criativa, ele é o alicerce que sustenta a criação. Entendemos que essa produção estética correlaciona a realidade e a imaginação de uma forma muito particular. A produção criativa sustenta-se fortemente em elementos da vivência do sujeito que se baseiam especialmente na realidade concreta. Assim, o poema é consolidado como elemento que busca uma produção estética mais fidedigna aos elementos do concreto ou do conhecimento científico. Essa interpretação é fortalecida pela ausência da animação do Universo e de entidades inanimadas. Dessa forma, há o indício de que a estudante tem a intenção de fazer com que sua poesia represente o real, diferentemente do poema "Ó Universo", que faz uso de metáforas compostas pela animação do Universo, Sol e Lua.

\section{CONCLUSÕES E CONSIDERAÇÕES FINAIS}

As poesias apresentadas expressam tanto aspectos cognitivos quanto aspectos responsivos, afetivos, morais e criativos. As poesias mostram a capacidade de as/os estudantes criarem e se utilizarem dos conteúdos aprendidos em sala de aula para a interpretação da realidade, condição essencial para uma formação crítica. Mostram ainda o poder de síntese e criatividade, posto que os poemas produzidos dialogam com a $\mathrm{SD}$ e também com os elementos comuns à ciência e às artes vistos com Bronowski - imaginação, criação, linguagem. Os quatro poemas analisados foram suficientes para um mapeamento das potencialidades expressivas e interpretativas das/os estudantes, permitindo vislumbrar posicionamentos relativamente consistentes diante dos saberes com os quais foram confrontados durante a SD.

Quadro 1. Síntese das categorias apresentadas nos poemas

\begin{tabular}{|c|l|l|l|l|}
\hline Poema & $\begin{array}{l}\text { Questionamento da } \\
\text { realidade }\end{array}$ & $\begin{array}{l}\text { Problematização do } \\
\text { saber humano }\end{array}$ & $\begin{array}{c}\text { Posicionamento } \\
\text { valorativo }\end{array}$ \\
\hline Eis a questão & $\begin{array}{l}\text { Realidade inatingível } \\
\text { (imensidão) }\end{array}$ & $\begin{array}{l}\text { Conflito totalidade }- \\
\text { particularidade }\end{array}$ & $\begin{array}{l}\text { Descentração humana } \\
\text { (eufórica) }\end{array}$ \\
\hline Ó Universo & $\begin{array}{l}\text { Universo teleológico } \\
\text { finalidades maiores) }\end{array}$ & $\begin{array}{l}\text { Limitações humanas } \\
\text { (mito da caverna) }\end{array}$ & $\begin{array}{l}\text { Insignificância humana } \\
\text { (disfórica) }\end{array}$ \\
\hline Apenas o Infinito & $\begin{array}{l}\text { Algo além do micro e e } \\
\text { do macro }\end{array}$ & $\begin{array}{l}\text { Respostas não são o } \\
\text { suficiente }\end{array}$ & $\begin{array}{l}\text { Insuficiência do saber } \\
\text { (disfórica) }\end{array}$ \\
\hline $\begin{array}{c}\text { Imaginação e } \\
\text { Realidade }\end{array}$ & $\begin{array}{l}\text { A realidade está lá } \\
\text { fora, basta ir atrás }\end{array}$ & $\begin{array}{l}\text { Limites superáveis } \\
\text { pela imaginação }\end{array}$ & $\begin{array}{l}\text { Imaginação com } \\
\text { resposta (eufórica) }\end{array}$ \\
\hline
\end{tabular}

Fonte: os autores. 
Dois dos poemas, "Ó Universo" e "Apenas o Infinito", sugeriram limites frente à possibilidade de apreensão da realidade mediante a ciência, mobilizando, de forma tácita ou implícita, a figura divina sem, contudo, apresentarem claramente uma defesa da experiência religiosa. É possível, no entanto, considerar uma estratégia discursiva diante da autoridade representada pela figura do professor, tacitamente em defesa da Ciência. Cabe notar, porém, a consistência interna desses poemas na articulação desse posicionamento, que, ainda que sutil, é firme e crítico, e pode muito bem dar-se mais por um ceticismo idealista do que propriamente místico. Ambos posicionam a busca científica em uma categoria disfórica, seja pela insignificância humana, seja pela insuficiência existencial das respostas científicas. Nada disso implica também um desconhecimento ou recusa aos saberes apresentados na SD: eles foram mobilizados, incorporados e articulados criticamente por meio de uma expressão estética e imaginativa. Retomando Lopes (2005, p. 417), os alunos beberam tanto na ciência quanto nas artes para a produção das poesias.

Os dois outros poemas aproximam-se mais de um posicionamento materialista e encaram a ciência de forma eufórica, sugerindo resoluções para os impasses representados pelas dificuldades de apreensão do real. Assim como os dois outros poemas, articularam os saberes que circularam em aula sem recair em mera repetição. Empregando o desafio estético como canal para expressão crítica, os estudantes expressaram os saberes emoldurados em um posicionamento ideológico consistente ao longo do poema.

Três categorias permitiram-nos compreender a natureza dos assuntos e posicionamentos presentes nas poesias, que denotam diferentes valores quanto à afetividade e à cognição, a saber: questionamento da realidade; problematização do saber bumano; posicionamento valorativo. As análises indicaram-nos aspectos da produção criativa dos estudantes, que desenvolveram processos de dissociação e associação visando a produção estética. Os poemas exibiram diferentes orientações para a realidade, com emprego de conceitos trabalhados em sala de aula para sustentar os posicionamentos dos estudantes. Tal fato nos indica a apropriação de ferramentas culturais (conceitos), visto que há o uso das mesmas em um contexto autônomo, em que os estudantes podiam selecionar temas e produzir com grande grau de liberdade. Assim, a conexão entre estética e cognição foi, a nosso ver, satisfatoriamente realizada, abrindo espaço para investigações futuras.

As poesias apresentam pouca variação na estrutura composicional, fato que é compreensível, uma vez que elas foram produzidas por estudantes do ensino fundamental que estão em processo de formação. Do ponto de vista da composição estrutural das poesias, há predominância de poemas com estrofes estáveis, seja no tamanho da frase ou no número de linhas. Apesar da estabilidade estrutural das poesias, não podemos entender que a produção estética seja estável, uma vez que se constitui da articulação entre a estrutura composicional e os conteúdos e valores presentes nas obras. Todas as poesias versam sobre os assuntos desenvolvidos em sala de aula, porém os enfoques e apreciações são distintos, o que podemos relacionar com o 'olhar singular de cada artista'.

Este estudo traz, a nosso ver, contribuições para pensar atividades que estão orientadas para a interação entre a Arte e a Ciência, seja no âmbito da pesquisa ou da educação em ciências. A partir das perspectivas que contribuem para compreender as interfaces entre a Ciência e a Arte, tomamos como ponto de partida a crítica à dicotomia entre esses campos da atividade humana. As relações entre a Arte e a Ciência são estabelecidas por meio de diversos aspectos, dentre os quais destacamos: imaginação, criatividade, percepção, afetividade e experiência. Ressaltamos também que tais relações são incapazes de deturpar as distintas formas de apreensão da realidade empenhadas pela Ciência e pela Arte. Tais interfaces, além de permitirem uma compreensão complementar entre as áreas, podem corroborar também para o ensino de ciências.

A aprendizagem, por sua vez, articula aspectos cognitivos e afetivos, que estão orientados para os objetos de ensino e para a realidade. A defesa do uso articulado entre a Ciência e a Arte para atividades educativas está pautada nas múltiplas dimensões que podem ser estabelecidas entre a cognição e o afeto, fato que pode contribuir para o posicionamento crítico diante da realidade e a ciência, além da apropriação de novas ferramentas culturais. Os resultados e as discussões aqui apresentadas permitem desdobramentos para a pesquisa na área da educação, especialmente quanto ao uso didático de instrumentos e atividades instauradas na interface entre Ciência e Arte. Para além da apropriação de ferramentas culturais e da responsividade que foram proporcionadas pela produção de 
poesias, estas podem também criar contextos de interatividade entre os estudantes e os professores, fenômeno que não foi possível investigar neste trabalho.

\section{REFERÊNCIAS}

BHATHAL, R. S. Physics and poetry. Physics Education, v. 7, n. 3, p. 129-132, 1972.

BRONOWSKI, J. Um sentido de futuro. Brasília: UNB, 1977.

. Ciência e valores humanos. Belo Horizonte: Itatiaia; São Paulo: Ed. da Universidade de São Paulo, 1979.

O olho visionário: ensaios sobre arte, literatura e ciência. Brasília: UNB, 1998

CAMARGO, D.; BULGACOV, Y. L. M. A perspectiva estética e expressiva na escola: articulando conceitos da psicologia sócio-histórica. Psicologia em Estudo, v. 13, n. 3, p. 467-475, 2008. http://dx.doi.org/10.1590/S1413-73722008000300007

CARTWRIGHT, J. Science and literature: towards a conceptual framework. Science $\boldsymbol{\&}$ Education, v. 16, n. 2, p 115-139, 2007. https://doi.org/10.1007/s11191-005-4702-9

FERREIRA, F. R. Ciência e arte: investigações sobre identidades, diferenças e diálogos. Educação e Pesquisa. São Paulo, v. 36, n. 1, p. 261-280, 2010. http://dx.doi.org/10.1590/S1517$\underline{97022010000100005}$

FIORIN, J. L. Elementos de análise do discurso. 15ª ed. São Paulo: Contexto, 2011.

GIORDAN, M. Computadores e linguagens nas aulas de ciências. Ijuí: Editora Unijuí, 2015.

GIRALDELLI, C. G.; ALMEIDA, M. J. P. M. Leitura coletiva de um texto de literatura infantil no ensino fundamental: algumas mediações pensando o ensino das ciências. Ensaio: Pesquisa em Educação em Ciências, v.10, n.1, p. 44-63, 2008. http://dx.doi.org/10.1590/1983-21172008100104

GONZÁLEZ REY, F. L. El lugar de las emociones en la constitución social de lo psíquico: El aporte de Vigotski. Educação \& Sociedade, n. 70, p. 132-148, 2000. http://dx.doi.org/10.1590/S0101$\underline{73302000000200006}$

GOUVEIA, R. S. Educação em Ciências, Cultura e Cidadania: A poesia na sala de aula. Gazeta de Física, v. 27, n. 4, p. 40-43, 2004.

GROTO, S. R.; MARTINS, A. F. P. Monteiro Lobato em aulas de ciências: aproximando ciência e literatura na educação científica. Ciência \& educação, v. 21, n.1, p.219-238, 2015. http://dx.doi.org/10.1590/1516-731320150010014

LIMA, G. S. O professor e a divulgação científica: apropriação e uso em situações formais de ensino. (Tese de doutorado) FE/USP, São Paulo, 2016. Recuperado de http://www.teses.usp.br/teses/disponiveis/48/48134/tde-16082016-093959/pt-br.php

LOPES, T. Luz, arte, ciência... ação! História, Ciências, Saúde - Manguinhos, Rio de Janeiro, v. 12 (suplemento), p. 401-418, 2005. http://dx.doi.org/10.1590/S0104-59702005000400021 
MEDVIÉDEV, P. N. O método formal nos estudos literários: introdução crítica a uma poética sociológica. São Paulo: Contexto, 2012.

MOREIRA, I. C. Poesia na aula de ciências? A literatura poética e possíveis usos didáticos. Física na Escola. v. 3, n. 1, p. 17-23, 2002.

MOREIRA, I. C.; MASSARANI, L. (En)canto científico: temas de ciência em letras da música popular brasileira. História, Ciências, Saúde - Manguinhos, v. 13 (suplemento), p. 291-307, 2006. http://dx.doi.org/10.1590/S0104-59702006000500018

PESSOA, F. Mensagem. Coleção a obra-prima de cada autor. São Paulo: Martin Claret, 2002.

PINO, A. A produção imaginária e a formação do sentido estético. Reflexões úteis para uma educação humana. Pro-Posições, v. 17, n. 2 (50), 2006. https://periodicos.sbu.unicamp.br/ojs/index.php/proposic/article/view/8643628/11147

POE, E. A. Eureka: a prose poem. New York: Leavitt, Trow \& CC, 1848.

REIS, J. C.; GUERRA, A.; BRAGA, M. Ciência e arte: relações improváveis? História, Ciências, Saúde - Manguinhos, v. 13 (suplemento), p. 71-87, 2006. http://dx.doi.org/10.1590/S0104$\underline{59702006000500005}$

SILVA, S. S. Narrativa literária e ciência. Ciência \& Ensino, v. 1, n. 1, p. 3-8, 2006.

SILVEIRA, M. P.; ZANETIC, J. Formação de Professores e Ensino de Química: Reflexões a partir do Livro Serões de Dona Benta de Monteiro Lobato e da Pedagogia de Paulo Freire. ALEXANDRIA: Revista de Educação em Ciência e Tecnologia, v.9, n.2, p.61-85, 2016. https://doi.org/10.5007/1982-5153.2016v9n2p61

SNOW, C. P. The two cultures and the scientific revolution. New York: Cambridge University Press, 1959.

TATIT, L. A abordagem do texto. In: FIORIN, J. L. (org.). Introdução à Linguística - I. Objetos teóricos. $4^{\mathrm{a}}$ ed. São Paulo: Contexto, 2005, p. 187-210.

VIGOTSKI, L. S. Psicologia pedagógica. $2^{a}$ ed. São Paulo: Martins fontes, 2004(a).

Imagination and Creativity in Childhood. Journal of Russian and East European

Psychology, v. 42, n. 1, p. 7-97, 2004(b). https://doi.org/10.1080/10610405.2004.11059210

A construção do pensamento e da linguagem. 2. ed. São Paulo: Martins Fontes, 2009.

ZANETIC, J. Física também é cultura. Tese (Doutorado). Faculdade de Educação da USP. São Paulo: Universidade de São Paulo, 1990.

Física e cultura. Ciência e Cultura, v. 57, n. 3, p. 21-24,

2005. http://cienciaecultura.bvs.br/scielo.php? script=sci arttext\&pid=S0009-67252005000300014

. Física e literatura: construindo uma ponte entre as duas culturas. História, Ciências, Saúde - Manguinhos, v. 13 (suplemento), p. 55-70, 2006b. http://dx.doi.org/10.1590/S0104$\underline{59702006000500004}$ 
Física e arte: uma ponte entre duas culturas. Pro-Posições, v. 17, n. 1 (49), p. 39-57, 2006. https://periodicos.sbu.unicamp.br/ojs/index.php/proposic/article/view/8643654/11171

Submetido: $06 / 11 / 2018$

Aprovado: 18/05/2019

Contato:

Nome completo

Rua/Av/etc., número, complemento

Cidade |Estado(sigla) | Pais

CEP 14.025-710 